\title{
Experimental facility for development of high-temperature reactor technology: instrumentation needs and challenges
}

\author{
Piyush Sabharwall $^{1^{*}}$, James E. O'Brien ${ }^{1}$, SuJong Yoon ${ }^{1}$, and Xiaodong Sun ${ }^{2}$ \\ ${ }^{1}$ Idaho National Laboratory, PO Box 1625, Idaho Falls, ID 83415-3860, USA \\ 2 Mechanical and Aerospace Engineering, Ohio State University, Columbus, Ohio, USA
}

Received: 1 May 2015 / Received in final form: 8 October 2015 / Accepted: 2 November 2015 Published online: 11 December 2015

\begin{abstract}
A high-temperature, multi-fluid, multi-loop test facility is under development at the Idaho National Laboratory for support of thermal hydraulic materials, and system integration research for high-temperature reactors. The experimental facility includes a high-temperature helium loop, a liquid salt loop, and a hot water/ steam loop. The three loops will be thermally coupled through an intermediate heat exchanger (IHX) and a secondary heat exchanger (SHX). Research topics to be addressed include the characterization and performance evaluation of candidate compact heat exchangers such as printed circuit heat exchangers (PCHEs) at prototypical operating conditions. Each loop will also include an interchangeable high-temperature test section that can be customized to address specific research issues associated with each working fluid. This paper also discusses needs and challenges associated with advanced instrumentation for the multi-loop facility, which could be further applied to advanced high-temperature reactors. Based on its relevance to advanced reactor systems, the new facility has been named the Advanced Reactor Technology Integral System Test (ARTIST) facility. A preliminary design configuration of the ARTIST facility will be presented with the required design and operating characteristics of the various components. The initial configuration will include a high-temperature $\left(750{ }^{\circ} \mathrm{C}\right)$, high-pressure $(7 \mathrm{MPa})$ helium loop thermally integrated with a molten fluoride salt $\left(\mathrm{KF}-\mathrm{ZrF}_{4}\right)$ flow loop operating at low pressure $(0.2 \mathrm{MPa})$, at a temperature of $\sim 450{ }^{\circ} \mathrm{C}$. The salt loop will be thermally integrated with the steam/water loop operating at PWR conditions. Experiment design challenges include identifying suitable materials and components that will withstand the required loop operating conditions. The instrumentation needs to be highly accurate (negligible drift) in measuring operational data for extended periods of times, as data collected will be used for code and model verification and validation, one of the key purposes for the loop. The experimental facility will provide a much-needed database for successful development of advanced reactors and provide insight into the needs and challenges in instrumentation for advanced high-temperature reactors.
\end{abstract}

\section{Introduction}

Effective and robust high-temperature heat transfer systems are fundamental to successful deployment of Advanced High Temperature Reactor (AHTR) systems for both power generation and non-electric applications. A highly versatile test facility is needed to address research and development (R\&D) and component qualification needs. Key activities of this test facility would include (1) qualification and testing of critical components in a hightemperature, high-pressure environment, (2) materials development and qualification, and (3) manufacturer and supplier evaluation and development. A small-scale test loop could provide for early testing of components and

\footnotetext{
* e-mail: Piyush.Sabharwall@inl.gov
}

design options that require special development tests before finalizing the design of AHTR components and qualifying them for operation in the larger loop or demonstration facility. Since a suitable facility does not exist for testing advanced reactor heat transfer system components (e.g., intermediate heat exchanger [IHX], valves, etc.), reactor internals, or the interface with the heat application plant, a laboratory-directed research and development project was approved to initiate development of such a facility at Idaho National Laboratory. This facility will include three thermally coupled flow loops: a high-temperature He loop, a liquid salt intermediate loop, and a high-pressure water loop. Based on its relevance to advanced reactor systems, the new facility has been named the Advanced Reactor Technology Integral System Test (ARTIST) facility.

AHTR plant designs often include an intermediate heat transfer loop (IHTL) with heat exchangers at either end to 


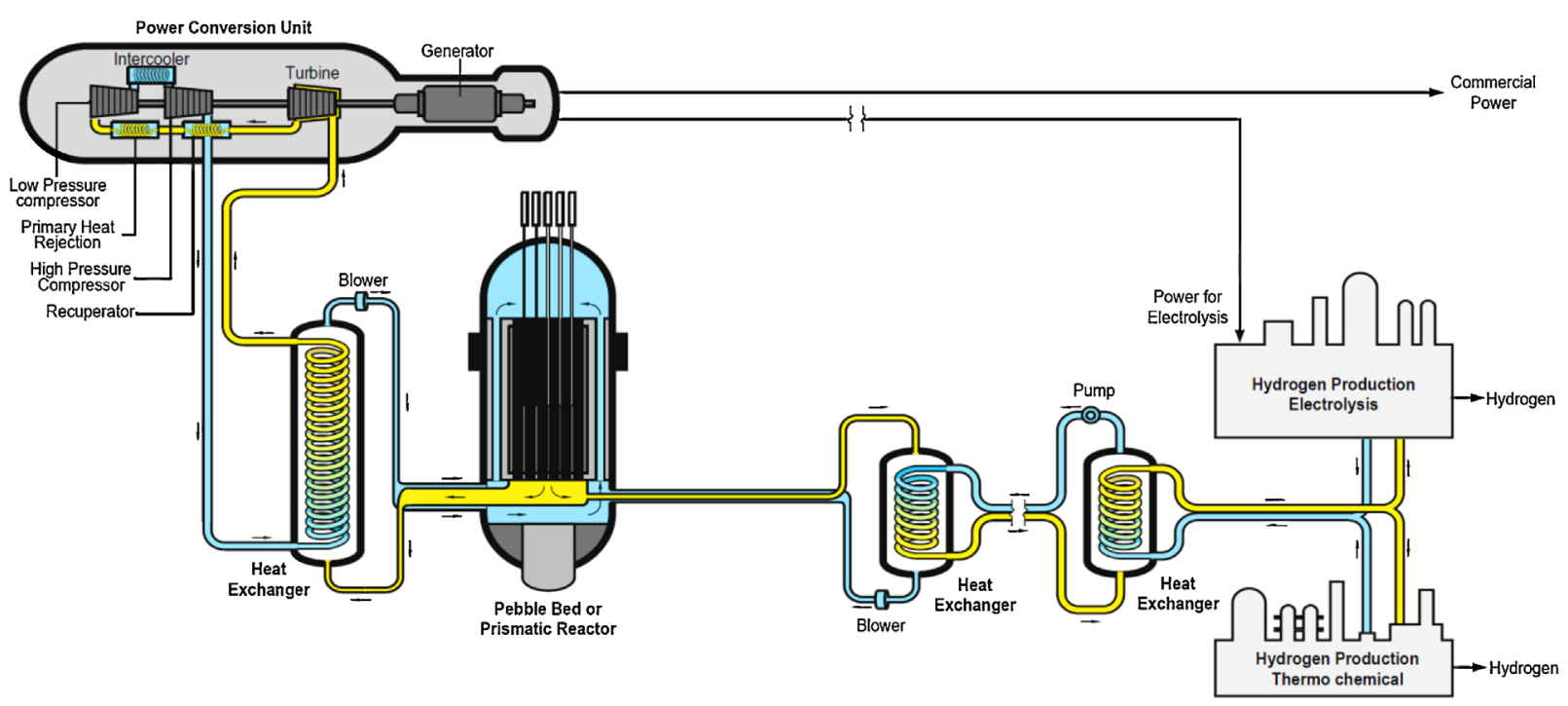

Fig. 1. NGNP power and hydrogen production plant with three IHXs.

deliver thermal energy to the application while providing isolation of the primary reactor system. A conceptual layout for one such plant, the Next Generation Nuclear Plant (NGNP), is shown in Figure 1. This concept indicates the use of a single IHX isolating the secondary power conversion unit working fluid from the primary He reactor coolant. For safety reasons and further isolation of the primary coolant from the process heat application (e.g., hydrogen production), a secondary heat exchanger is included in the process heat loop. In this case, a full intermediate heat transport loop is required, with an appropriate heat transport fluid.

Liquid salts have been identified as excellent candidate heat transport fluids for intermediate loops, supporting several types of advanced high temperature reactors [1-4]. Liquid salts have also been proposed for use as a primary coolant for the Advanced High Temperature Reactor (AHTR) [5] and the Fluoride Salt-cooled High-Temperature Reactor (FHR) [6,7]. Fluoride salt-coolants are eutectic binary or tertiary mixtures of fluoride salts with melting points in the range of 320 to $500{ }^{\circ} \mathrm{C}$. FHRs have reactor outlet temperatures of $600{ }^{\circ} \mathrm{C}$ or higher for highefficiency power generation or process heat applications. Liquid salts exhibit superior heat transfer characteristics compared to He-cooled reactors. FHRs can also take advantage of effective passive natural circulation for decay heat removal.

PCHEs are strong candidate heat exchangers for intermediate heat transport loops due to their very high power density, requiring much less material per unit of heat duty compared to conventional shell and tube heat exchangers. PCHEs are fabricated from individual flat plates into which small flow channels are etched. The plates are stacked into alternating hot/cold layers and are typically diffusion-bonded, yielding a monolithic heat exchanger with strength equal to that of the base material.

With appropriate materials, these heat exchangers can operate at high temperature and high pressure. PCHEs can, however, be susceptible to large thermal stresses during transient thermal hydraulic events [8].
In addition to the heat exchangers, each flow loop in the ARTIST facility will include high-temperature test sections operating at prototypical conditions that can be customized to address specific research issues associated with each working fluid. Possible research topics for the hightemperature helium test section include flow distribution, bypass flow, heat transfer in prototypical prismatic core configurations under forced and natural circulation conditions $[9,10]$, parallel flow laminar instability during pressurized cooldown [11,12], and turbulent heat transfer deterioration $[13,14]$. Oxidation effects associated with water or air ingress could also be examined [15].

The high-temperature test section in the liquid salt loop can be used for examination of materials issues, thermal stresses, and heat transfer. Metallic materials have been studied extensively in liquid salt environments [1-3], but additional research is needed to evaluate the performance of ceramic and composite materials such as $\mathrm{SiC} / \mathrm{SiC}$ in liquid salt environments [7]. Fundamental heat transfer issues for liquid salts are related to the fact that these are highPrandtl-number fluids with high viscosities and specific heats, and relatively low thermal conductivities. Accordingly, prototypical Reynolds numbers are small, in the laminar or transitional flow regimes and heat transfer enhancement strategies (e.g., extended surfaces) may have to be employed in the core and other components. Flow geometries of interest include prototypical prismatic core configurations and pebble beds, as well as heat exchanger flow passages. The high Prandtl number reduces the potential for thermal shock (compared to low-Prandtlnumber liquid metal coolants), but the possibility of large thermal stresses still exists [7]. Bypass flow can also be an issue for prismatic reactor core configurations with liquid salt coolants.

The liquid salt loop will include a thermal energy storage (TES) system for support of thermal integration studies. The TES system will be based on freezing and melting of the salt acting as a high-temperature phase change material (PCM). A number of salts have been proposed as high-temperature PCMs for solar energy 
applications $[16,17]$. The advantage of using a PCM is that thermal energy can be supplied to the process at a nearly constant temperature, taking advantage of the latent heat of melting.

The high-temperature test section in the steam/water loop will be used primarily for prototypic evaluation of new cladding materials and accident-tolerant fuels. It will be designed to characterize the thermal, chemical, and structural properties of candidate advanced fuel cladding materials and designs under various simulated flow and internal heating conditions to mimic operational reactor conditions prior to in-reactor testing. The capability for out-of-pile mock-up testing of candidate (surrogate) fuelclad systems is essential for reactor readiness, in particular when innovative fuel cladding will be in direct contact with the test reactor primary coolant system without secondary containment. Careful control of water chemistry will be essential for these studies; a water chemistry control section is included in the design of the loop.

Flow-induced vibration of fuel rod bundles has been identified as an important issue for sodium-cooled reactors [18]. The high-temperature test section of the hot water loop can also potentially be used to study flow-induced vibration of simulated sodium-cooled reactor fuel rod bundles. Hot water at $200^{\circ} \mathrm{C}$ and $1.38 \mathrm{MPa}$ matches the density of sodium. This condition is well within the operational range of the proposed loop.
Research conducted in these flow loops will also support verification and validation efforts. Experimental data for validation is required to gain confidence in the existing theoretical and empirical correlations. Development of such an experimental database is needed to advance the technology readiness level of various reactor concepts and high-temperature components (such as heat exchangers). The database will also be used to evaluate the performance of existing models and correlations in predicting thermal hydraulic phenomena. New models and/or correlations will be developed as needed. The facility is designed such that each individual loop can operate independently.

\section{Facility description}

A process flow diagram for the multi-fluid, multi-loop test facility is shown in Figure 2. The facility includes three thermally interacting flow loops: helium, liquid salt, and steam/water. The helium loop will be initially charged from pressurized gas storage cylinders to the loop operating pressure of $7 \mathrm{MPa}$. The loop can be evacuated prior to charging for removal of air. This process can be repeated with intermediate gas venting via the deaeration vent to achieve the desired loop He purity level. Helium flow through the loop will be driven by a water-cooled centrifugal gas circulator rated for high-pressure service, with a design flow rate up to

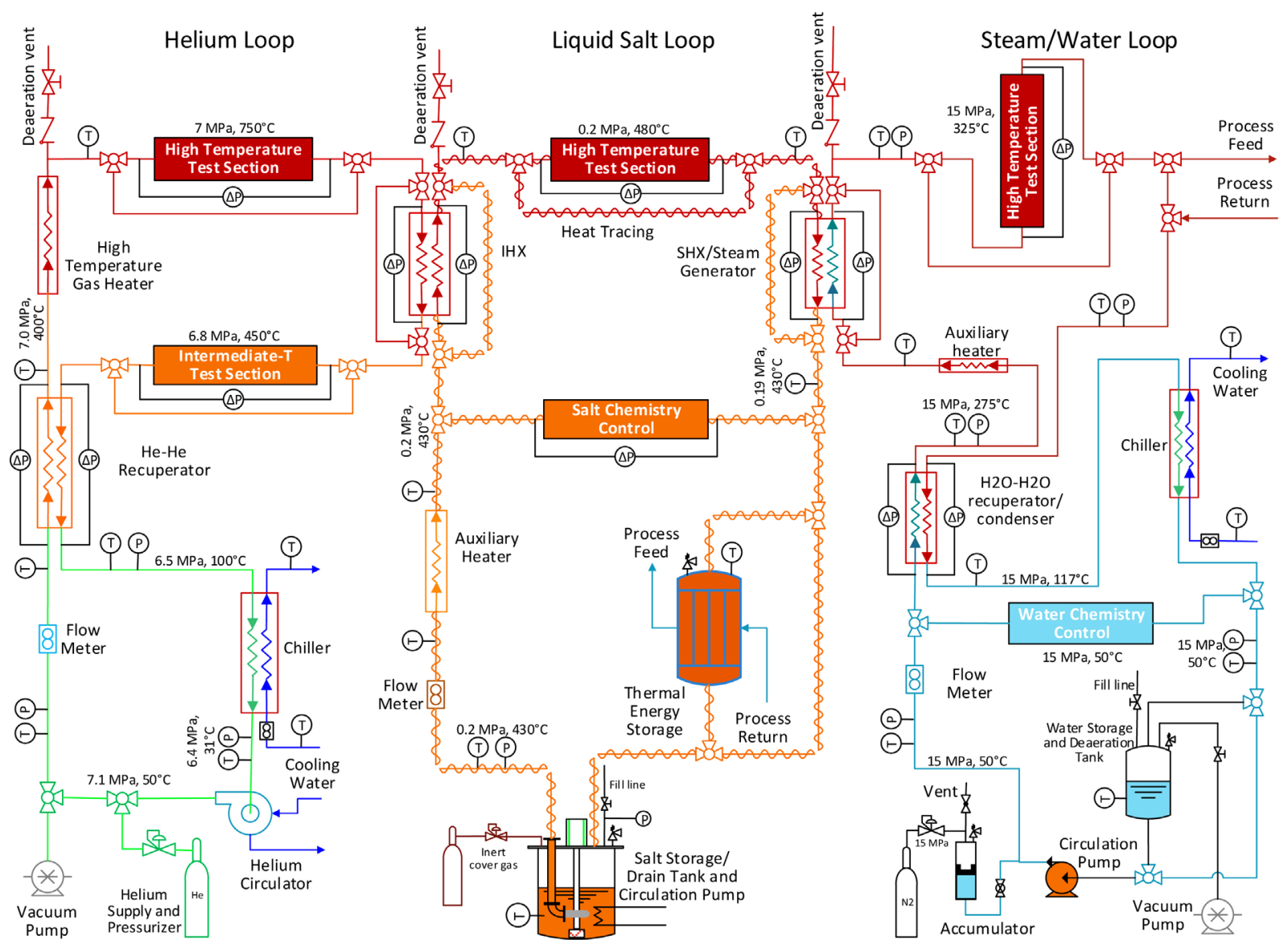

Fig. 2. Schematic of multi-fluid, multi-loop ARTIST thermal hydraulic test facility. 
$525 \mathrm{LPM}$ at $7 \mathrm{MPa}$ (11,300 SLPM) and a loop pressure drop of $100 \mathrm{kPa}$. The circulator flow rate will be controlled by means of a variable-frequency drive coupled to the motor. The helium circulator will be designed to operate with a maximum helium temperature of $100^{\circ} \mathrm{C}$. It is therefore located in the low-temperature section of the helium flow loop. The gas is preheated to intermediate temperature by flowing through a helium-to-helium recuperator $(60 \mathrm{~kW}$ duty) that transfers heat from the intermediate-temperature helium return flow to the low-temperature stream. The hightemperature portion of the flow loop is designed to handle helium temperatures up to $800^{\circ} \mathrm{C}$. This temperature will be achieved using a high-temperature in-line electrical gas heater located downstream of the recuperator. The nominal power requirement for the high-temperature gas heater is $60 \mathrm{~kW}$.

The helium loop will include a high-temperature test section for heat transfer and materials studies. Downstream of the test section, the helium gas flows through a heat exchanger where heat will be transferred to the adjacent liquid salt loop using a scaled version of an IHX. The baseline design for this heat exchanger will be a highefficiency compact microchannel PCHE with a nominal heat duty of $55 \mathrm{~kW}$. Analysis of a PCHE operating with $\mathrm{He}$ as the hot fluid and liquid salt as the cold fluid is provided in reference [8]. Downstream of the IHX, the helium flows through an intermediate-temperature test section and the recuperator to transfer heat back to the inlet stream. Downstream of the recuperator, the helium flows through a water-cooled chiller $(10 \mathrm{~kW})$ to cool it down to the gas circulator operating temperature. The baseline design for the He-He recuperator will also be a PCHE. In addition to its heat recuperation role, this heat exchanger simulates an IHX for the case in which He is used as an intermediate heat transfer fluid, albeit at lower operating temperatures. Performance data obtained from this recuperator will provide useful validation data for the reactor system application. The He-He version of the IHX operates with essentially balanced high pressure on both sides, minimizing the possibility of leakage of primary fluid to the secondary side.

The center part of Figure 2 shows the liquid salt portion of the multi-loop facility. The loop will be charged with salt from the salt storage tank. This tank will include a heater designed to heat the frozen salt to a temperature above its melting point. The head space in the salt storage tank will be maintained at slightly elevated pressure with an inert cover gas. The inert gas will prevent in-leakage of air or moisture, minimizing the potential for salt contamination. During startup, liquid salt will drain to the pump inlet by gravity, with assist from the cover gas pressure, as needed. The salt pump will be designed to operate at $450{ }^{\circ} \mathrm{C}$ at low pressure $(\sim 0.2 \mathrm{MPa})$. It will provide salt flow rates up to 20 LPM. A standard stainless steel such as SS316 may be suitable for the pump material, but other alloys will also be considered. The entire liquid salt flow loop will be heattraced to prevent salt from freezing and causing a flow blockage. Downstream of the pump, the salt flow rate will be measured using a high-temperature ultrasonic flow transducer. The salt temperature will be boosted as needed to the desired intermediate temperature using an in-line electrical auxiliary heater. Careful control of salt chemistry will be critical for successful operation of this loop; a salt chemistry control section will be installed at the intermediate temperature location. The salt temperature will increase to $\sim 480^{\circ} \mathrm{C}$ as it flows through the IHX and heat is transferred from the helium loop to the salt loop. Note that the He-salt IHX will have high-pressure helium on one side and low-pressure salt on the other, establishing the potential for high-temperature creep and leakage of primary He into the salt loop, emphasizing the need for demonstrating complete IHX integrity at prototypical conditions.

For independent operation of the liquid salt loop, the IHX will not be required. An IHX bypass will enable salt flow directly to the high-temperature test section without the pressure drop associated with the IHX. The auxiliary heater will be designed to independently heat the salt to the maximum operating temperature of $480{ }^{\circ} \mathrm{C}$ even when the IHX is bypassed. Its nominal design heater power will be $75 \mathrm{~kW}$. Downstream of the high-temperature test section, the liquid salt flows through the SHX, transferring heat to the tertiary steam/water loop. A bypass line around the SHX is also provided for cases in which the salt loop will be operated independently of the steam/water loop. The salt can then flow directly back to the pump or it can flow through a thermal energy storage (TES) system for process integration studies.

The right-hand side of Figure 2 shows the steam/water tertiary loop. The SHX can serve as a steam generator or simply a single-phase heat exchanger, depending on conditions to be simulated in the tertiary loop. For most tests, conditions in the tertiary loop will be intended to simulate conditions in the primary loop of a pressurized water reactor (PWR). PWR conditions will be needed for materials/corrosion studies of accident-tolerant fuels, new cladding materials, crud formation, etc. Alternately, at lower operating pressure the tertiary loop can simulate the secondary side of a PWR system, with steam generation for process integration studies. Flow through the hot water loop will be produced by a pump designed to operate at $15 \mathrm{MPa}$ with a nominal water flow rate of $5.7 \mathrm{LPM}$ at $15 \mathrm{MPa}$ and $40^{\circ} \mathrm{C}$.

Downstream of the pump, the water flows through a recuperator designed to recover heat from the hightemperature portion of the loop. The baseline recuperator inlet and outlet water temperatures will be $50^{\circ} \mathrm{C}$ and $275^{\circ} \mathrm{C}$, respectively. The water is heated further to $325^{\circ} \mathrm{C}$ by heat transfer in the SHX. For cases in which the SHX is not present or is bypassed, an auxiliary heater will be used to achieve the desired $325^{\circ} \mathrm{C}$ test section inlet temperature. Note that the SHX will also operate with a large pressure differential between the water side $(15 \mathrm{MPa})$ and the salt side $(0.2 \mathrm{MPa})$, establishing the potential for water leakage into the salt, and emphasizing the need to demonstrate full SHX integrity at these conditions. High-temperature creep should not be a concern at these temperatures. However, at $15 \mathrm{MPa}$, the maximum water temperature $\left(325^{\circ} \mathrm{C}\right)$ is well below the saturation temperature, so the water remains in the liquid phase throughout the system for the baseline case. The high-temperature test section in the water loop will have a vertical orientation to support boiling (at 
pressures lower than $15 \mathrm{MPa}$ ) and/or natural circulation studies. Simulated PWR core geometries in the test section will support research on new cladding materials, accidenttolerant fuels, etc. Hot water or steam can be supplied to other co-located processes or experiments via the process feed and process return lines. After flowing through the return side of the recuperator, the water temperature is decreased to $117^{\circ} \mathrm{C}$. It is further reduced to the pump operating temperature of $50^{\circ} \mathrm{C}$ by means of a water-cooled chiller. Pressure in the hot water loop will be maintained by means of a piston accumulator with regulated nitrogen on the gas side. The water storage and deaeration tank will be plumbed to a vacuum pump to allow for air removal. The water can also be directed to flow through a chemistry control section. This part of the loop will be designed to establish the loop water chemistry. Most often, PWR water chemistry will be established. The chemistry control section will include filtering, a water softener, and a reverse osmosis conditioner for deionization/demineralization. It will also provide the ability to establish the correct $\mathrm{pH}$ value to ensure prototypical PWR conditions.

A three-dimensional (3D) computer-aided design (CAD) model of the ARTIST experimental test facility has been developed using Pro-Engineering software. The CAD model includes all of the major facility components and piping. A rendering of the model is provided in Figure 3, with all of the components labeled. The facility is shown mounted on a large skid, measuring $4.9 \mathrm{~m}(16 \mathrm{ft}) \times 9.1 \mathrm{~m}$ $(30 \mathrm{ft})$. The highest component is at the $7.0 \mathrm{~m}(23 \mathrm{ft})$ elevation. Components in the helium loop are designated with the He- abbreviation, salt loop components with the LS- abbreviation, and water/steam loop components with the WS- abbreviation. Pipe supports and insulation are not shown in these figures. Each component is shown to scale according to the current status of the design. Notable features of the high-pressure helium and water loops include the large flanges on the piping sections. The lowtemperature sections of the He loop require class 600 flanges and NPS 2, schedule 160 piping. The hightemperature section of the He loop requires class 2500 flanges. Due to its higher pressure, the water/steam loop utilizes NPS 2, schedule 160 piping and class 2500 valves and flanges throughout. As an alternative to large flanges, the use of Grayloc connectors will also be examined.

The geometry of the He-He recuperator and the IHX shown in Figure 3 is based on a baseline PCHE design, sized

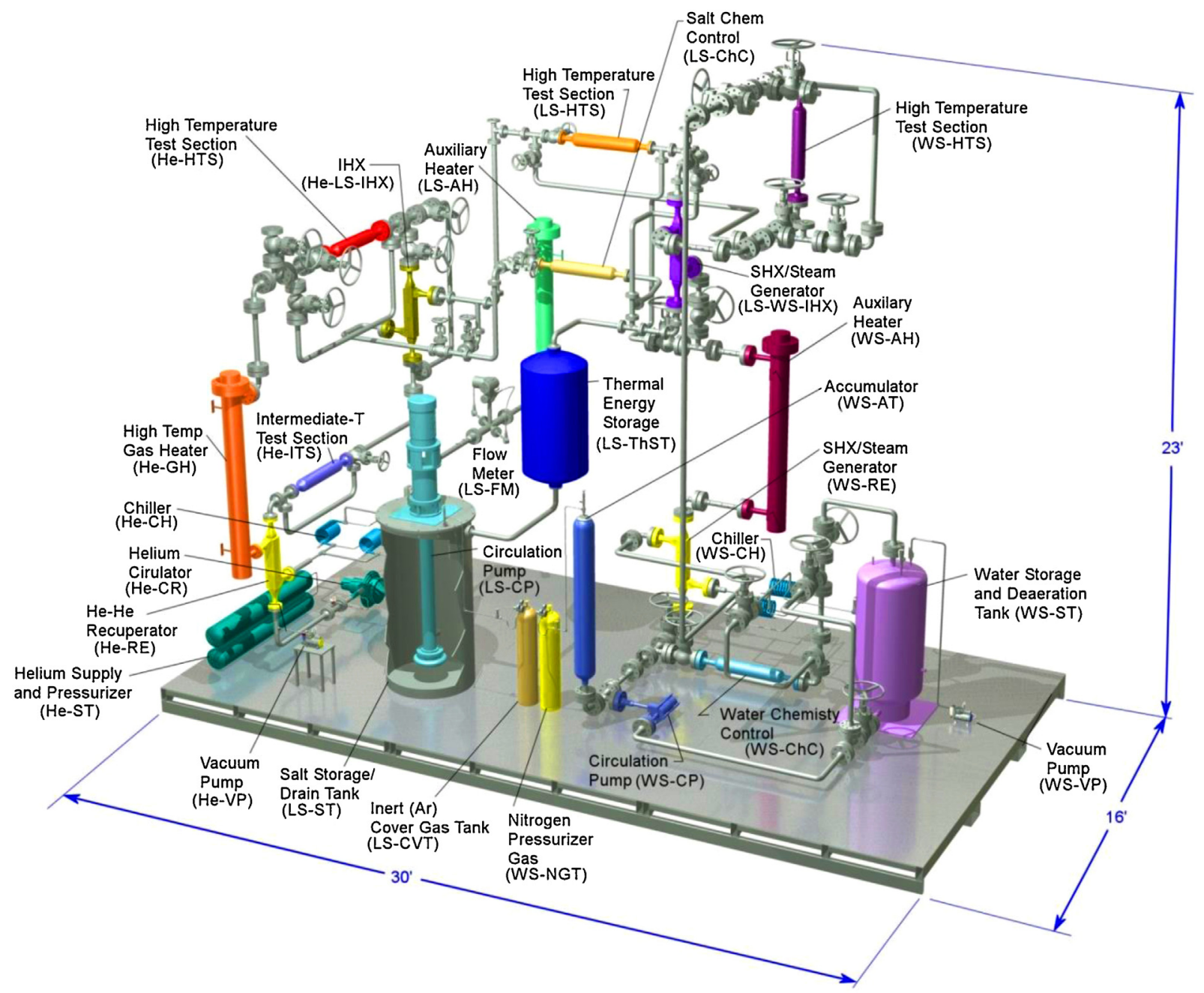

Fig. 3. 3D CAD model of the ARTIST facility. 
to support the design helium flow rate and the required heat duty. The exact dimensions of these heat exchangers may change, depending on the final design details and the vendor selected. The high-temperature gas heater is based on a Watlow circulation heater with alloy $800 / 800 \mathrm{H}$ sheaths and ANSI 600 class pressure rating. The valving arrangement shown in Figure 3, downstream of the hightemperature gas heater, allows for bypass of the hightemperature test section. Three valves are shown instead of a single three-way valve because a three-way valve rated for these temperatures and pressures has not yet been identified. The high-temperature and intermediate-temperature helium test sections as shown in Figure 3 are designed to accommodate small tube bundles or other geometries of interest. The instrumentation in the test sections and loops could potentially serve the dual purpose of measuring test parameters and demonstrating new highresolution advanced instrumentation and control equipment in challenging environments. The test sections will be custom-designed components and may be built in a range of sizes. As shown, the test sections have an outer diameter of $15.2 \mathrm{~cm}$ (6 in.) over a length of $0.76 \mathrm{~m}$, with a total length of $1.22 \mathrm{~m}$ between flanges.

The He circulator flow rate will be controlled by means of a variable-frequency drive coupled to the motor. The helium circulator will be designed to operate with a maximum helium temperature of $100^{\circ} \mathrm{C}$. The circulator geometry shown in Figure 3 is based on information received from Barber-Nichols for gas circulators with similar requirements. The He chiller is shown as two coiled tube-in-tube counter-flow heat exchangers arranged in parallel. The use of two parallel chillers provides the required flow area with off-the-shelf units. The vacuum pump for removing air from the loop is also shown.

The largest component of the salt loop is the storage/ drain tank. The current tank design size is $1 \mathrm{~m}$ diameter and $2 \mathrm{~m}$ high. This size is large enough to accommodate all of the salt in the loop and in the thermal energy storage system, while maintaining a high enough liquid salt level during operation to avoid any risk of gas entrainment into the pump. The salt storage/drain tank is not a pressure vessel because the salt loop operating pressure will be only slightly elevated above ambient pressure. The salt pump is a vertical cantilever pump, shown with a geometry based on a design for liquid salts available from Nagle. The ultrasonic flow meter (LS-FM) shown in Figure 3 is based on the Panaflow design from GE. The auxiliary heater is based on a Watlow circulation heater design with either alloy 600 or $800 \mathrm{H}$ heater element cladding materials.

The thermal energy storage tank in Figure 3 is shown with a diameter of $0.75 \mathrm{~m}$ and a height of $1.5 \mathrm{~m}$, providing a volume of $660 \mathrm{~L}$ and a thermal capacity of $978 \mathrm{MJ}$ or $272 \mathrm{~kW}-\mathrm{hr}_{\mathrm{th}}$, based on the latent heat of fusion for KF. It will be designed for operation as a high-temperature, phasechange, thermal energy storage system, using the fluoride salt working fluid of the salt loop as the phase-change material.

The water/steam loop is designed to operate at PWR conditions. The water storage and deaeration tank is sized to hold all of the purified water in the loop. It can be isolated from the flow loop and therefore it will not be designed for full loop pressure. Charging and draining of the loop will be performed at atmospheric pressure. As shown in the figure, the water storage tank has a diameter of $0.76 \mathrm{~m}$ and a height of $1.5 \mathrm{~m}$, with an internal volume of $695 \mathrm{~L}$, which is about 2.7 times larger than the estimated total loop water volume, therefore providing storage for excess purified water plus a gas space for air removal. The water circulation pump will operate at $15 \mathrm{MPa}$, providing a loop flow rate of at least $350 \mathrm{~kg} / \mathrm{h}(2.5 \mathrm{gpm})$ against a loop pressure drop of $20 \mathrm{kPa}$. Loop pressure will be set and maintained using a bladder accumulator pressurized by nitrogen gas. The commercially available accumulator is $0.24 \mathrm{~m}$ in diameter and $2.0 \mathrm{~m}$ high. The auxiliary heater will be a custom-engineered circulation heater housed in a class-2500 pressure vessel. The water chiller will consist of two parallel, tube-in-tube, water-cooled, counter-flow heat exchangers rated for $15 \mathrm{MPa}$ service. Depending on the laboratory capabilities, the cooling water will be either once-through tap water or circulated house water cooled by a facility chiller.

\section{Instrumentation}

A variety of sensors and other diagnostic tools will be employed in the ARTIST facility to continuously monitor system parameters. The instrumentation used in the loop will provide real-time input to the data acquisition system regarding system flow rate, temperatures and pressures at various locations in the test section and composition information for chemistry control. Conditions at several locations in this system will be particularly challenging for instrumentation. A preliminary assessment of instrumentation requirements and suitable hardware (preferably commercially available) has been completed.

Instrumentation utilized for the loop will also provide first-hand information on long-term reliability and drift performance. Most high-temperature loops do not deal with coolants such as fluoride salts, where corrosion can be a significant challenge, especially at higher temperatures. Maintaining a pressurized $\mathrm{He}$ system at $750^{\circ} \mathrm{C}$ with negligible leakage is also a major long-term challenge.

Instrumentation will be installed at various locations in the loop to monitor temperature, pressure, liquid level, chemistry (where appropriate/needed) and flow conditions for safety of the loop and gather data to support verification and validation efforts. Operating temperatures in the loops will be actively maintained via a closed-loop feedback control system.

\subsection{Helium loop}

\subsubsection{Chemistry/Impurities and moisture}

The baseline He loop chemistry is pure helium. However, even ultra-high-purity (UHP) helium contains trace impurities such as $\mathrm{H}_{2} \mathrm{O}, \mathrm{O}_{2}$, hydrocarbons, $\mathrm{CO}, \mathrm{CO}_{2}, \mathrm{~N}_{2}$, and $\mathrm{H}_{2}$. For UHP He, these impurities are in the low parts-per-million (ppm) range and the overall purity is specified as $99.999 \%$. However, additional impurities will enter the gas during loop operation, especially when high-temperature operation is 
initiated. Furthermore, some gases may have to be intentionally included as additives. For example, low levels of oxygen may be needed to maintain protective oxide scale on metallic components [1]. On the other hand, oxygen can corrode graphite in the vessel core, which can in turn release additional gases such as $\mathrm{CO}$ and $\mathrm{CO}_{2}$. These gases can subsequently form deposits on metallic components. Careful monitoring and control of these gases will be critical for successful long-term operation of the He loop. Monitoring is usually performed by withdrawing a gas sample from the low-temperature part of the loop for analysis using a gas chromatograph (GC) system.

\subsubsection{Flow rate}

Flow rate in the He loop will be measured in the lowtemperature $\left(\sim 50{ }^{\circ} \mathrm{C}\right)$ leg of the loop just downstream of the circulator. There are several options for measuring helium flow rate including thermal mass flow meter, coriolis meter, venturi meter, or vortex flow meter. For this closed-loop high-flow-rate helium flow system, one of the major costs will be the circulator and its cost will increase with loop pressure drop. Therefore, a low-pressure-drop flow measurement device is desired. The permanent pressure loss for vortex flow meters is quite low, and they provide excellent accuracy with pressure and temperature compensation to yield a true mass flow measurement. Commercial units that meet the pressure and temperature specifications for the helium flow loop are available from several vendors. Thermal mass flow meters with laminar flow elements will also be considered if the pressure drop is low enough.

\subsubsection{Pressure: absolute and differential}

Pressure instrumentation for the helium loop will include several absolute pressure transducers, as indicated in Figure 2, plus several differential pressure transducers (dP cells). The differential transducers will be used primarily to measure pressure drop across the IHX and the recuperator. In some cases, differential pressure may be needed across the high-temperature test section as well. The differential transducers will be designed to measure relatively small pressure differences while operating at high absolute pressure. Each differential transducer assembly will include a dP cell manifold that allows zeroing of the cell at high absolute pressure.

\subsubsection{Temperature}

Temperature measurements for the helium loop will mostly be acquired using type $\mathrm{K}$, stainless-steel or inconel-sheathed ungrounded $1 / 8$ - or $1 / 16$-in. thermocouples inserted into the flow stream using compression fittings. Inconel sheathing will be used on the high-temperature portion of the loop. Type $\mathrm{K}$ thermocouples are rated for service up to $1260^{\circ} \mathrm{C}$. The high-temperature gas heater will be feedback-controlled using the temperature just downstream of the heater as the process variable.

\subsection{Salt loop}

Instrumentation specification for the salt loop will adapt to lessons learned from researchers at the University of Wisconsin, The Ohio State University, and Oak Ridge National Laboratory, based on their recent experiences in salt loop development.

\subsubsection{Chemistry control}

Pretreatment of fluoride salts is necessary before introducing them to the flow loop, to remove oxygen, moisture, and other contaminants from the mixture. In addition, continuous monitoring and chemistry control will be necessary to monitor and remove any contaminants such as metal oxides that build up in the mixture as a result of interaction with loop materials or due to air or moisture ingress. Monitoring may include the use of a high temperature electrochemical oxygen sensor based on yttria-stabilized zirconia (YSZ) or yttria-doped thoria (YDT) [19]. Development of a continuous chemistry monitoring system for the salt loop will be an important aspect of the loop design process.

\subsubsection{Flow rate}

Most standard flow measurements include some kind of probe or sensor in direct contact with the fluid. Many of these are not appropriate for the liquid salt application. The measurement environment is very challenging both in terms of temperature and materials compatibility. Ultrasonic flow meters can be used for this application. Nonintrusive clamp-on ultrasonic flow meters are attached to the outside of a section of pipe with no fluid contact. These are available from several vendors. Wetted ultrasonic flow meters are permanently mounted on a spool piece; they provide higher accuracy [20], but appropriate materials must be selected for the pipe body and the sensor heads.

\subsubsection{Pressure and delta- $P$}

A particularly important measurement for this loop will be the pressure drop across the IHX and the SHX. Pressure measurements will be challenging in the salt loop. The minimum requirement is that the transducer can operate at temperatures above the melting point of the salt. Melt pressure transducers operate by hydraulic transmission of pressure through a low-vapor-pressure incompressible liquid from a wetted diaphragm to a measurement diaphragm located away from the high temperature fluid [21]. NaK is commonly used as a hydraulic transmission fluid for high-temperature melt pressure transducers. It has a freezing point that is well below room temperature $\left(\sim-12.8^{\circ} \mathrm{C}\right)$ and a boiling point of $785^{\circ} \mathrm{C}$. NaK-filled melt pressure transducers operate over a temperature range up to $538^{\circ} \mathrm{C}$, which is an excellent match for the salt loop operating temperature range. Unfortunately, these transducers are generally only commercially available for high pressure 
ranges (lowest range is typically $0-10 \mathrm{MPa}$ ), whereas the salt loop will operate at low pressure $(\sim 0.2 \mathrm{MPa})$. The molten salt loop at ORNL uses a NaK-buffered pressure transducer that prevents overheating of the transducer electronics [22]. A direct diaphragm displacement pressure measurement probe has also been researched at ORNL and U. of TN for a molten salt loop application [23]. This probe incorporated a nickel diaphragm for a direct capacitance sensor-based measurement. Specification and selection of absolute and differential pressure transducers for the molten salt loop will be a design challenge to be addressed during the detailed design phase.

\subsubsection{Temperature}

For the liquid salt loop, type $\mathrm{K}$ inconel-sheathed ungrounded $1 / 8$ - or $1 / 16$-in. thermocouples inserted into the flow stream using compression fittings will be used for most loop temperature measurements. Surface-mounted thermocouples will also be used to provide the process variable measurements required for feedback control of the heat-traced sections of piping and vessel walls in the salt loop.

\subsubsection{Liquid level}

Liquid level in the salt storage tank will change during system startup and shutdown. Liquid level in the salt storage tank will be obtained using non-contact hightemperature ultrasonic or microwave level transmitters.

\subsection{Water/Steam loop}

\subsubsection{Chemistry control}

The water flow loop includes a chemistry control section. Water chemistry control is critical for proper simulation of PWR conditions. Control of water chemistry parameters in an operating PWR is aimed at striking a balance between assuring the integrity of the primary system pressure boundary, the integrity of the fuel cladding, and to minimize out-of-core radiation fields [24]. For example, elevated $\mathrm{pH}$ can reduce out-of-core radiation fields, but can also lead to elevated lithium levels that can lead to alloy 600 cracking. Low $\mathrm{pH}$ values can lead to increased crud deposits. Operation at $\mathrm{pH}$ values of $6.9-7.4$ is generally recommended. $\mathrm{pH}$ control is achieved by controlling the boric acid $\left(\mathrm{H}_{3} \mathrm{BO}_{3}\right)$ concentration $(\sim 500 \mathrm{ppm})$ and the lithium $(\mathrm{LiOH})$ concentration $(\sim 2.2 \mathrm{ppm})$. Corrosion experiments with simulated PWR water chemistry generally follow these guidelines [25]. In addition, minimization of dissolved oxygen to $<5 \mathrm{ppb}$ is desired. Small amounts of dissolved hydrogen can be included in PWR water to maintain reducing conditions and to eliminate radiolytically produced oxygen.

Instrumentation for the water loop will include in-line $\mathrm{pH}$ and dissolved oxygen sensors. Both of these sensors will be installed in the low-temperature part of the water loop.
These sensors are available from a number of vendors with ranges that are suitable for this application.

\subsubsection{Flow rate}

Flow rates in the water loop will be measured at full loop pressure (up to $15 \mathrm{MPa}$ ) and at low temperature $\left(\sim 50^{\circ} \mathrm{C}\right)$. The biggest challenge for this flow meter is the pressure, which is higher than the standard pressure rating on most off-the-shelf thermal or coriolis mass flow meters and controllers. GE does offer a high-pressure coriolis flow meter (RHM015) that is suitable for pressures up to $70 \mathrm{MPa}$, with a wide range of flow rates. Alternately, turbine flow meters are available from several manufacturers with standard pressure ratings of $35 \mathrm{MPa}$ or higher over a wide range of flow rates.

\subsubsection{Pressure and delta-P}

Pressure instrumentation for the water loop will include several absolute pressure transducers, as indicated in Figure 2, plus several differential pressure transducers. The differential transducers will be used primarily to measure pressure drop across the SHX and the recuperator. In some cases, differential pressure may be needed across the high temperature test section as well. The differential transducers will be designed to measure relatively small pressure differences while operating at high absolute pressure. Each differential transducer assembly will include a $\mathrm{dP}$ cell manifold that allows zeroing of the cell at high absolute pressure.

\subsubsection{Temperature}

For the water loop, type $\mathrm{K}$ inconel-sheathed ungrounded $1 / 8$ - or $1 / 16$-in. thermocouples inserted into the flow stream using compression fittings will be used for most loop temperature measurements.

\section{Conclusions}

A conceptual design for a new high-temperature, multifluid, multi-loop test facility has been presented in this study. This facility will support thermal hydraulic materials, and thermal energy storage research for nuclear and nuclear-hybrid applications. Three flow loops will be included: a high-temperature helium loop, a liquid salt loop, and a hot water/steam loop. The three loops will be thermally coupled through an intermediate heat exchanger (IHX) and a secondary heat exchanger (SHX). The salt loop is representative of an advanced reactor system intermediate heat transfer loop. Advanced reactor systems often include an intermediate heat transfer loop (IHTL) with heat exchangers at either end to deliver thermal energy to the application while providing isolation of the primary reactor system. Liquid salts have been identified as excellent candidate heat transport fluids for intermediate 
loops, supporting several types of advanced high temperature reactors. Liquid salts have also been proposed for use as a primary coolant for the Advanced High Temperature Reactor (AHTR) and the Fluoride Salt-cooled HighTemperature Reactor (FHR).

Engineering research topics to be addressed with this facility include the characterization and performance evaluation of candidate compact heat exchangers such as printed circuit heat exchangers (PCHEs) at prototypical operating conditions, flow and heat transfer issues related to core thermal hydraulics in advanced helium-cooled and salt-cooled reactors, and evaluation of corrosion behavior of new cladding materials and accident-tolerant fuels for LWRs at prototypical conditions. Research performed in this test facility will advance the state of the art and technology readiness level of high temperature intermediate heat exchangers (IHXs) for nuclear applications while establishing INL as a center of excellence for the development and certification of this technology. The thermal energy storage capability will support research and demonstration activities related to process heat delivery for a variety of hybrid energy systems and grid stabilization strategies.

Fundamental research topics will also be addressed with this facility. Each loop will include a high-temperature test section for this purpose. Research topics that may be studied in the high temperature helium test section include flow distribution, bypass flow, and heat transfer in prototypical prismatic core configurations under forced and natural circulation conditions, parallel flow laminar instability during pressurized cooldown, and turbulent heat transfer deterioration. Oxidation effects associated with water or air ingress could also be examined. The high temperature test section in the liquid salt loop can be used for examination of materials issues, thermal stresses, and high-Prandtl-number heat transfer issues. The high temperature test section in the steam/water loop will be used primarily for prototypic evaluation of new cladding materials and accident-tolerant fuels. It will be designed to characterize the thermal, chemical, and structural properties of candidate advanced fuel cladding materials and designs under a variety of simulated flow and internal heating conditions to mimic operational reactor conditions prior to in-reactor testing. The liquid salt loop will also include thermal energy storage (TES) system for support of thermal integration studies. The TES system will be based on freezing and melting of the salt acting as a hightemperature phase change material (PCM).

Conceptual design will be completed for all three loops as proposed, but the construction of each individual loop will depend on testing needs and future funding.

\section{References}

1. D.F. Williams, K.T. Clarno, L.M. Toth, Assessment of candidate liquid-salt coolants for the Advanced HighTemperature Reactor (AHTR) ORNL/TM-2006/12, Oak Ridge National Laboratory, Tennessee, 2006

2. D.F. Williams, K.T. Clarno, Evaluation of salt coolants for reactor applications, Nucl. Technol. 163, 330 (2008)
3. M.S. Sohal, M.A. Ebner, P. Sabharwall, P. Sharpe, Engineering database of liquid salt thermophysical and thermochemical properties, INL/EXT-10-18297, Idaho, 2010

4. O. Benes, C. Cabet, S. Delpech, P. Hosnedl, V. Ignatiev, R. Konings, D. Lecarpentier, O. Matal, E. Merle-Lucotte, C. Renault, J. Uhlir, Assessment of liquid salts for innovative applications, ALISIA Deliverable (D-50), European Commission, Euratom Research and Training Programme on Nuclear Energy, 2009

5. C.W. Forsberg, The advanced high-temperature reactor: high-temperature fuel, liquid salt coolant, liquid-metalreactor plant, Prog. Nucl. Energy 47, 32 (2005)

6. R.O. Scarlat, P.F. Peterson, The current status of fluoride salt-cooled high-temperature reactor (FHR) technology and its overlap with HIF target chamber concepts, Nucl. Inst. Methods Phys. Res. A. 733, 57 (2013)

7. N.Zweibaum, G. Cao, A.T. Cisneros, B. Kelleher, M.R. Laufer, R. O. Scarlat, J.E. Seifried, M.H. Anderson, C.W. Forsberg, E. Greenspan, L.W. Hu, P.F. Peterson, K. Sridharan, Phenomenology, methods, and experimental program for fluoride-salt-cooled high temperature reactors, Prog. Nucl. Energy 77, 390 (2014)

8. E. Urquiza, K. Lee, P.F. Peterson, R. Grief, Multiscale transient thermal, hydraulic, and mechanical analysis methodology of a printed circuit heat exchanger using an effective porous media approach, J. Therm. Sci. Eng. Appl. 5, 041011-1 (2013)

9. R.S. Schultz et al., Next generation nuclear plant methods technical program plan, INL/EXT-06-11804, Idaho, 2007

10. Y. Tung, R.W. Johnson, Y. Ferng, C. Chieng, Bypass flow computations on the LOFA transient in a VHTR, Appl. Therm. Eng. 62, 415 (2014)

11. E. Reshotko, Analysis of laminar instability problem in gascooled nuclear reactor passages, AIAA J. 5, 1606 (1967)

12. G. Melese, R. Katz, Thermal and flow design of helium-cooled reactors (ANS, Illinois, 1984)

13. D.M. McEligot, J.D. Jackson, Deterioration criteria for convective heat transfer in gas flow through non-circular ducts, Nucl. Eng. Design 232, 327 (2004)

14. J.I. Lee, P. Hehzlar, P. Saha, M.S. Kazimi, Studies of the deteriorated turbulent heat transfer regime for the gas-cooled fast reactor decay heat removal system, Nucl. Eng. Design 237, 1033 (2007)

15. D. Chapin, S. Kiffer, J. Nestell, The very high temperature reactor: a technical summary (MPR Associates, 2004)

16. A. Hoshi, D.R. Mills, A. Bittar, T.S. Saitoh, Screening of high melting point Phase Change Materials (PCM) in solar thermal concentration technology, Solar Energy 79, 332 (2005)

17. J.C. Gomez, High-temperature Phase Change Materials (PCM) candidates for thermal energy storage applications, NREL Report, NREL/TP-5500-51446, 2011

18. E. Bojarsky, H. Deckers, H. Lehning, P.H. Reiser, L. Schmidt, THIBO experiments - thermohydraulically induced fuel pin oscillations in Na-cooled reactors, Nucl. Eng. Design 130, 21 (1991)

19. L. Meyer, Challenges related to the use of liquid metal and molten salt coolants in advanced reactors, TECDOC-1696 (IAEA, Austria, 2013)

20. GE Measurement and Control Brochure, Panaflow HT panametrics ultrasonic SIL flow meter for liquids, 2014

21. Gefran Brochure, Melt pressure transducers and transmitters, 2014

22. G.L. Yoder, A. Aaron, B. Cunningham, D. Fugate, D. Holcomb, R. Kisner, F. Peretz, K. Robb, J. Wilgen, D. Wilson, An 
experimental test facility to support development of the fluoridesalt-cooled high-temperature reactor, Ann. Nucl. Energy 64, 511 (2014)

23. J.A. Ritchie, Pressure measurement instrumentation in a high temperature molten salt test loop, MS Thesis, U. of Tennessee, 2010
24. PWR Primary Water Chemistry Guidelines, EPRI Technical Report, TR-105714-V1R4, 1999

25. T. Terachi, T. Yamada, T. Miyamotot, K. Arioka, K. Fuku, Corrosion behavior of stainless steels in simulated PWR primary water - Effect of chromium content in alloys and dissolved hydrogen, J. Nucl. Sci. Technol. 45, 975 (2008)

Cite this article as: Piyush Sabharwall, James E. O'Brien, SuJong Yoon, Xiaodong Sun, Experimental facility for development of high-temperature reactor technology: instrumentation needs and challenges, EPJ Nuclear Sci. Technol. 1, 14 (2015) 